\title{
Body fat measurement in Indian men: Comparison of three methods based on a two-compartment model
}

\author{
DS BHAT ${ }^{1}$ MSc, CS YAJNIK ${ }^{1}$ MD, KN RAUT ${ }^{1}$ MSW, H LUBREE ${ }^{1}$ MSc, S REGE ${ }^{1}$ \\ MSc, SD CHOUGULE ${ }^{1}$ MSW, MG SAYYAD ${ }^{1}$ MSc, P SHETTY ${ }^{2} \mathrm{PhD}$, JS YUDKIN ${ }^{3}$ \\ FRCP, A KURPAD ${ }^{4} \mathrm{PhD}$ \\ ${ }^{1}$ Diabetes Unit, King Edward Memorial (K.E.M.) Hospital and Research Centre, \\ Rasta Peth, Pune-11, India \\ ${ }^{2}$ Food and Agricultural Organisation, Rome, Italy \\ ${ }^{3}$ International Health and Medical Education Centre, University Collage London, UK \\ ${ }^{4}$ Department of Physiology, St. Johns Hospital, Bangalore, India
}

\section{Short title}

Body fat in Indian men

Key words:

Indian men, obesity, adiposity, total body water, fat free mass

\section{Author for correspondence}

Dr. Chittaranjan S. Yajnik, M.D.

Director, Diabetes Unit, K.E.M. Hospital and Research Centre,

Rasta Peth, Pune-11, India

Tel: (020) 6111958

Fax: (020) 6125603

e-mail: diabetes@vsnl.com

web: www.kemdiabetes.com 


\begin{abstract}
Obesity is a major risk factor for diabetes and related disorders. The current classification of obesity is based on body mass index $\left(\mathrm{BMI} \mathrm{kg} / \mathrm{m}^{2}\right.$ ) which is a surrogate for the total body fat. Since the relationship between BMI and body fat varies in different populations an independent validation of the BMI - body fat relationship in the population of interest is required. We studied the validity of field methods of measuring body fat as well as the relationship between BMI and accurately measured body fat (by deuterium dilution) in middle-aged Indian men in rural and urban Pune. We measured total body fat by 3 techniques: deuterium dilution method $\left(\mathrm{D}_{2} \mathrm{O}\right.$ method, criterion method), anthropometry (multiple skin folds) and bioelectrical impedance analysis (BIA) in 141 healthy men (30-50y) selected by multistage stratified random sampling from rural and urban Pune. The men were $39.3( \pm 6.2)$ years old and had a BMI of $21.9( \pm 3.6) \mathrm{kg} / \mathrm{m}^{2}$. Mean total body fat was $14.3 \mathrm{~kg}(23.0 \%)$ by anthropometry, $16.5 \mathrm{~kg}(26.1 \%)$ by BIA and $15.3 \mathrm{~kg}(24.6 \%)$ by $\mathrm{D}_{2} \mathrm{O}$ method. Although there was good correlation between fat estimation by three methods ( $r=0.90 \mathrm{p}<0.001$ all), compared to $\mathrm{D}_{2} \mathrm{O}$ method anthropometry underestimated body fat by $1.0 \mathrm{~kg}$ and BIA overestimated fat by $1.2 \mathrm{~kg}(\mathrm{p}<0.001$ both). Using the standard cut-point of $25 \%$ body fat for adiposity $29.5 \%$ rural, $46.0 \%$ slum and $75.0 \%$ middle class men were adipose. These proportions were considerably higher than the number of men who were overweight (BMI $\geq 25-29.9 \mathrm{~kg} / \mathrm{m}^{2}$ rural $9.0 \%$, slum $22.0 \%$ and urban $27.0 \%$ ) and obese (BMI $>30 \mathrm{~kg} / \mathrm{m}^{2}$ slum $4.0 \%, 0 \%$ in rural and urban) by World Health Organisation (WHO) 2000 criteria. We found a good agreement between three commonly used 'two compartment' methods of body fat measurement in Indian men. The WHO cut-points for overweight and obese underestimate adiposity in middle aged Indian men. We recommend that future studies assessing and defining risk for chronic diseases in Indians should measure adiposity by anthropometry (multiple skinfolds) and BIA (calibrated for Indians) rather than relying only on BMI cutpoints.
\end{abstract}




\section{Introduction}

India is experiencing an epidemic of type 2 diabetes and related disorders (1-3). Obesity is a major risk factor for insulin resistance and type 2 diabetes. Body mass index (BMI, $\mathrm{kg} / \mathrm{m}^{2}$ ) is the most commonly used measure of obesity. BMI is easy to measure in clinical and epidemiological studies but it does not directly measure fat. Prevalence of obesity in a population is determined as the proportion above a BMI cut-point. This is thought to represent number of individuals with excess amount of body fat. The relationship between BMI and total body fat differs in different populations. It appears likely that Indians may have a different BMI - body fat relationship compared to Caucasians and African Americans since they are more adipose for a given BMI (4-8). Plus Ref 19. Plus the Y-Y picture. These findings are based on migrant Indians living in developed countries. We therefore studied the BMI - body fat relationship in rural and urban Indians in India.

Intrinsic to the accurate characterization of the body fat - BMI relationship is the accurate determination of total body fat. The easiest method to use in field situations is the model in which human body is divided into two-compartments: fat and fat free mass (FFM). Two such methods are anthropometry (multiple skinfolds) and bioelectrical impedance analysis (BIA) which indirectly measure body density and body water respectively. However these relatively easy to perform field methods require validation against a criterion method with minimal error. Deuterium dilution method $\left(\mathrm{D}_{2} \mathrm{O}\right)$ is simple to perform in large population samples and we used this as the criterion method to compare anthropometric and BIA measurements of body fat in Indian middle-aged men.

\section{Subjects and Methods}

This investigation is a part of the CRISIS (Coronary Risk of Insulin Sensitivity in Indian Subjects) study which investigated the relationship of body fat with insulin resistance and cardiovascular risk in middle aged Indian men.

We aimed at studying $\sim 150$ apparently healthy men between $30-50 \mathrm{y}$ of age from 3 residential areas in and around Pune (rural, urban slums and urban middle class). They were selected by multi-stage, stratified random sampling. Rural subjects were selected from 2 villages (Karandi and Dhamari) approximately $50 \mathrm{kms}$ from Pune city. Urban subjects were selected from 4/124 administrative wards in Pune City (2/55 slums and 2/69 urban middle class). Subjects were registered by a house-to-house survey and a total of 1222 men (30-50y) were listed. We measured height and weight to define distribution of BMI in the whole group. After excluding known cases of diabetes, hypertension and cardiovascular disease we approached 200 randomly selected subjects from each place with a view to study approximately 150 in each location. Finally we studied 441 subjects (149 rural, 142 slums and 150 middle class) The participation rate was rural $85 \%$, slums $80 \%$ and middle class $80 \% . \mathrm{D}_{2} \mathrm{O}$ studies were performed on a subset of 145 men from these 441 subjects. We selected approximately a similar number of subjects from each tertile of the BMI of the whole group irrespective of their place of residence, Subjects reported at the Diabetes Research Centre, KEM Hospital, Pune, the evening before the study. They were given a standard dinner after which they rested.

The study protocol was approved by the ethical committee of the KEM Hospital Research Centre, Pune, and by the local community leaders in the three study areas. Informed consent was signed by each subject. At end of methods

Deleted: in the CRISIS study. Deleted: Because of monetary constraints

Deleted:

Deleted: 9 


\section{Deuterated water method}

Five hours after dinner (about 01:00h) the subjects emptied their bladder completely to provide a basal urine sample. They then drank $75 \mathrm{mg}$ of deuterated water (Europa Scientific, Crewe, UK) per kg body weight from a sterile plastic container with the aid of a straw. This was followed by 3.0 gm per $\mathrm{kg}$ body weight of plain water using the same straw and container.

Urine samples were collected every hour between $4 \mathrm{~h}$ and $7 \mathrm{~h}$ after drinking deuterated water. Weight was measured after the last urine sample which was used for all calculations. Samples were frozen $\left(\right.$ at $\left.-70^{\circ} \mathrm{C}\right)$ until transported to St. John's Medical College, Bangalore for further analysis. Deuterium enrichment was analysed by zinc reduction followed by dual-inlet massspectroscopy (Europa Scientific, Crewe, UK) as recommended by the IDECG (9) and as described earlier (10). Each sample was analysed in duplicate and the mean was used for analysis. The sample dose of deuterated water was also analysed to ascertain its enrichment and this was adjusted in the calculation of the total body water (TBW). This value was down adjusted by $4 \%$ for hydrogen exchange to calculate the true TBW (11). Fat free mass (FFM) was calculated using a hydration constant of 0.732 (12) and the difference between the body weight and FFM was taken as total body fat.

\section{Anthropometric measurements}

Three specially trained observers performed all measurements. Height was measured to the nearest $0.1 \mathrm{~cm}$ using a wall fixed stadiometer (CMS Instruments, London) and body weight was recorded to the nearest $0.1 \mathrm{~kg}$ using a portable scale (Soehnle Waagen $\mathrm{GmBH}$, Germany). The biceps, triceps, subscapular and suprailiac skinfold thicknesses were measured on the non dominant side of the body using Harpenden skinfold callipers (CMS Instruments, London). Intra/inter observer repeatability?

Durnin and Womersley's equations (13) were used to calculate body density from the sum of skinfold thicknesses, and Siri's equation (14) to calculate body fat from body density. Subtracting body fat in kilograms from total body weight calculated FFM.

\section{Bioelectrical impedance}

The measurement was carried out at a frequency of $50 \mathrm{kHz}$ (Multiscan 5000, Bodystat Ltd, Isle of Man, UK) according to the recommendations in the NIH Technology Assessment Conference Statement (15). A specific Bodystat calibrator (500 ohms) was used daily to confirm the reproducibility of the machine. (results of reproducibility?) BIA test was carried out in the morning (fasting) after the subject had emptied bladder. For each subject, the impedance value and TBW calculated by the manufacturer's software were both recorded. The manufacturer's software calculates TBW using a equation generated on 236 European Caucasian males with a wide range in age, height and body weight (information provided by manufacturer).
Deleted: Subjects reported at the Diabetes Research Centre, KEM Hospital, Pune, the evening before the study. They were given a standard dinner after which they rested. 9 


\section{Statistical analysis}

Data is presented as mean and standard deviation (SD). Statistical significance of the difference between measurements obtained by three methods was tested by the paired t-test. Difference between group means was tested by the independent t-test. The anthropometric and BIA measurements of body fat were correlated with the criterion method $\left(\mathrm{D}_{2} \mathrm{O}\right)$ by Pearson's method. The bias and limits of agreement in relation to the criterion method were assessed by Bland-Altman method (16). We used multiple linear regression analysis to study the relationship between body fat measurement $\left(\mathrm{D}_{2} \mathrm{O}\right.$ method) and its determinants (impedance value and anthropometric measurements). All statistical analyses were performed using Statistical Package for Social Sciences (SPSS) for Windows (version 10.0).

\section{Results}

Of 145 subjects who participated in the study, three subjects who had low impedance values and therefore negative body fat mass were excluded from the analysis. These subjects were not significantly different from the whole group with respect to anthropometry and biochemistry and we could not find any methodological explanation for the unusually low readings. One subject had a very low body fat by $\mathrm{D}_{2} \mathrm{O}$ method $(1.4 \mathrm{~kg}, 2.6 \%$ body fat) probably because of technical reasons and was also excluded. The following analysis is therefore on 141 subjects.

There was no significant difference in the anthropometric characteristics of the parent group $(\mathrm{n}=441)$ and the study group $(\mathrm{n}=142)$ (Table 1 ) would it be better to compare those included and those not studied? In the study group the range of heights and weights of the subjects were $149.8-180.7 \mathrm{~cm}$ and $37.8-100.6 \mathrm{~kg}$ respectively, giving a BMI range of $15.1-34.5$ $\mathrm{kg} / \mathrm{m}^{2}$.

TBW values obtained by the $\mathrm{D}_{2} \mathrm{O}$ technique (criterion method) ranged from 23.4 to $48.6 \mathrm{~kg}$, FFM values ranged from 32.0 to $66.4 \mathrm{~kg}$ and body fat from 3.8 to $34.1 \mathrm{~kg}$. This represented $9.2-40.4 \%$ of body weight (Table 2 ). The anthropometric method estimated body densities $(1.02-1.07 \mathrm{~kg} / \mathrm{L})$ giving total body fat 4.4 to $31.7 \mathrm{~kg}$ which represented 11.3 to $36.2 \%$ of body weight. In the BIA method the primary estimate was TBW (using software) which ranged from 24.9 to 42.7 .4 (???) $\mathrm{kg}$ giving FFM of 34.1 to $58.4 \mathrm{~kg}$ and total body fat of 1.0 to $42.2 \mathrm{~kg}$ ( 2.7 to $43.2 \%$ of body weight). The anthropometric and BIA methods correlated strongly with the $\mathrm{D}_{2} \mathrm{O}$ method $(\mathrm{r}=0.90, \mathrm{p}<0.001$, both). However, there were small but significant differences between the values measured by these methods (is correlation fair - or Bland Altman?) Anthropometric method underestimated body fat by a mean of $1.0 \mathrm{~kg}$, $(\mathrm{p}<0.001)$ while the BIA technique overestimated it by a mean of $1.2 \mathrm{~kg},(\mathrm{p}<0.001)$ in comparison to the $\mathrm{D}_{2} \mathrm{O}$ method. To assess the agreement between the $\mathrm{D}_{2} \mathrm{O}$, anthropometry and BIA methods we used Bland and Altman technique (16). The difference from the $\mathrm{D}_{2} \mathrm{O}$ method was plotted against the mean of the two methods and the limits of agreement (2SD) between the methods were calculated (Fig $1 \mathrm{a}$ and $1 \mathrm{~b}$ ).

The anthropometric method gave a smaller mean fat mass difference of $1.0( \pm 2.5) \mathrm{kg}($ Fig $1 \mathrm{a})$ while the BIA method gave a mean fat mass difference of $-1.2( \pm 3.3) \mathrm{kg}$ from the $\mathrm{D}_{2} \mathrm{O}$ method $\left(\mathrm{D}_{2} \mathrm{O}-\mathrm{BIA}\right)$ (bias $=6.5$ and $-7.8 \%$ respectively) (Fig $\left.1 \bar{b}\right)$. Both of these mean differences were significantly different from zero $(p<0.001)$.

For anthropometry the difference $\left(\mathrm{D}_{2} \mathrm{O}\right.$ - anthropometry) has no significant relationship with average value however for BIA the difference $\left(\mathrm{D}_{2} 0-\right.$ BIA $)$ was inversely related to the 
average value $(\mathrm{r}=-0.50, \mathrm{p}<0.001)$. Thus, at lower values BIA underestimated and at higher values it overestimated the fat mass (Figure $1 \mathrm{a}$ and $1 \mathrm{~b}$ ).

The predictive equation derived from this data set for body fat $\left(\mathrm{D}_{2} \mathrm{O}\right)$ is: Fat $(\mathrm{kg})=-8.021+$ 0.472 [height ${ }^{2} /$ impedance] $^{2} \mathrm{r}^{2}=0.31, \mathrm{p}<0.001$, standard error of estimate $5.4 \mathrm{~kg}$. Including body weight in the equation improved the prediction: Fat $(\mathrm{kg})=-12.297-0.287$ [height ${ }^{2}$ / impedance] +0.694 [weight], $\mathrm{r}^{2}=0.82, \mathrm{p}<0.001$, standard error of estimate $2.74 \mathrm{~kg}$. The latter predictive equation was internally validated by dividing the whole group randomly into two equal sized groups and inspecting the distribution of residuals (mean $=0.00, \mathrm{SD} \pm 2.7$ ) which is a normal distribution emphasizing the validity of the equation. Total body fat using this equation ranged from 3.7 to $34.7 \mathrm{~kg}$ (9.7 to $35.1 \%$ of body weight). There was a strong correlation between fat mass obtained from manufacturer's equation and the new predictive equation $(\mathrm{r}=0.92, \mathrm{p}<0.000)$, however, the software significantly over estimates the fat mass by $1.3 \mathrm{~kg}(\mathrm{p}=0.000)$ with limits of agreement -3.3 to $5.9 \mathrm{~kg}$.

\section{Body mass index and body fat percent}

We compared the relationship between body fat percent $\left(\mathrm{D}_{2} \mathrm{O}\right.$ method) and the BMI. The body fat percentage correlated strongly with the BMI $(r=0.88, p<0.001)$ (Figure 2). This was represented by equation: Fat $(\mathrm{kg})=-7.085+1.441 * \mathrm{BMI}$.

Extrapolating this line to a percent body fat of $25 \%$ gave a BMI of $22.3 \mathrm{~kg} / \mathrm{m}^{2}$. In addition, the number of subjects with a body fat above $25 \%$ was compared with the number of subjects | with a BMI of above $25 \mathrm{~kg} / \mathrm{m}^{2} .49 .3 \%$ of the subjects had body fat percent $>25 \%$ while 19.7 $\%$ had a BMI $>25 \mathrm{~kg} / \mathrm{m}^{2}$. 


\section{Discussion}

We found that in middle aged Indian men, body fat measured by the two field methods, anthropometry (Durnin's equation (13)) and bioelectrical impedance (Multiscan 5000, Bodystat) correlates strongly with that measured by the criterion method $\left(\mathrm{D}_{2} \mathrm{O}\right)$. However, anthropometric method underestimated and bioimpedance overestimated body fat by an average of about $2 \%$ compared to the $\mathrm{D}_{2} \mathrm{O}$ method. There was no systematic bias in anthropometric method but bioimpedance underestimated at lower and overestimated at higher degrees of adiposity. To the best of our knowledge this is the largest population based study comparing body composition methods in India. This paper reports our results in middleaged men, we will report our results on women in a subsequent paper.

There is little good quality data in Indians of body fat measured by appropriate techniques and only limited information on relation between BMI and body fat. Most of the studies are in Indians abroad (refs), the only Indian study reporting BIA measurements used invalidated manufacturer's equation.( ref). Our subjects had a large range of BMI and body fat, allowing for a better determination of a prediction equation for body fat. We used a criterion method that would have a precision of about $1 \mathrm{~kg}$ (in a $70 \mathrm{~kg}$ man, with $15 \%$ fat, and with $30 \mathrm{Litre}$ TBW), calculated by propagation of error with a $2 \%$ and $0.1 \mathrm{~kg}$ precision of measurement of TBW and weight respectively (Kurpad et al.). It would be ideal to use four-compartment model, with a higher degree of precision as the criterion method but it was not possible because of financial constraints and lack of appropriate technology. We chose $\mathrm{D}_{2} \mathrm{O}$ dilution as the criterion method which is relatively easy to perform in large number of subjects and is fairly accurate.

Despite a highly significant correlation between the criterion method and the skinfold and BIA measurement of body fat $(\mathrm{r}=0.90)$ there are significant limitations to interpretation of skinfold and BIA results. Mean body fat measurements for the group by $\mathrm{D}_{2} \mathrm{O}$ dilution, skinfolds method and bioimpedance were similar but the limits of agreement between the criterion method and the two field methods were rather large (for anthropometry -4.0 to 6.0 $\mathrm{kg}$ and for BIA -7.8 to $5.4 \mathrm{~kg}$ ) This implies that skinfold and bioimpedance fat measurements for an individual will have large limits of confidence and this fact should influence the interpretation of results. On a population basis, there was no systematic difference in the body fat measurement by skinfolds method in relation to $\mathrm{D}_{2} \mathrm{O}$ measurements, suggesting that skinfold fat measurement by Durnin's equation (10) may be used in Indians without any change in the prediction equation. This is welcome news for epidemiological studies which are able to use only this method of body fat measurement. We had not expected such a close relationship because Indians have a different distribution of subcutaneous fat and visceral fat compared to white Caucasians in whom the original equation was defined.

On the other hand, BIA measurement showed a systematic difference in body fat measurement compared to $\mathrm{D}_{2} \mathrm{O}$ method, underestimating it at lower and overestimating it at higher levels. This could exaggerate the prevalence estimates of adiposity in an adipose population, viz. urban Indians. Given the large limits of agreement between $\mathrm{D}_{2} \mathrm{O}$ and $\mathrm{BIA}$ methods, an individual result should be viewed with caution. There is therefore a need to devise new age and gender based Indian equations; this has been done for middle-aged Indian men in the present study. Our findings will have significant impact on the use and interpretation of results of portable BIA machines in India, either in clinical practice, gymnasiums offering 'slimming' programs or in research institutions. 
Finally, we compared the number of individuals who were classified 'overweight' and 'obese' by the currently used WHO cut-points for BMI and the number who have body fat percent $>25 \%$, an accepted definition of 'adiposity' in men. Of these middle-aged men $19.7 \%$ were overweight and obese but $49.3 \%$ were adipose ( $>25 \%$ body fat by $\mathrm{D}_{2} \mathrm{O}$ method). It is obvious that WHO BMI cut-points substantially underestimate adiposity in Indians. BMI cut-points are useful as population risk indicators for mortality as well as morbidity, the major component of which is the risk of type 2 diabetes. Two recent reports from India provide some support to our argument. Ten-year incidence risk of hyperglycaemia [Impaired glucose tolerance (IGT) + Diabetes Mellitus (DM)] in middle-age normal glucose tolerant Indians was increased 2.4 times by BMI $>23 \mathrm{~kg} / \mathrm{m}^{2}$. Similarly, in a large multi-centre cross sectional study of diabetes prevalence in India, BMI of $>23 \mathrm{~kg} / \mathrm{m} 2$ significantly predicted diabetes. Similar findings have been reported in Indians abroad and in other Asian populations (China and SE Asia) (deurenberg. et al (20)). This led to a WHO Expert Consultation (19) which recommended a reduction of BMI cut-point to $23 \mathrm{~kg} / \mathrm{m} 2$ for 'public health action point' in Asians. The next logical step in this process is to collect prospective morbidity and mortality data in relation to BMI in India and other Asian countries.

In summary, we report that multiple skinfold measurements and use of Durnin and Womersley's equation (13) provide an accurate estimate of body fat in middle aged Indian men compared to $\mathrm{D}_{2} \mathrm{O}$ method. We provide a new prediction equation to calculate body fat from electrical impedance measurements in Indians. We recommend that future studies of body fat (adiposity) in Indians should measure multiple skinfolds or use a specifically calibrated bioimpedance machine rather than rely solely on BMI cut-points of obesity.

Conflicts: Dr. CS Yajnik and Dr. A Kurpad were invited experts for the WHO Expert Consultation on Appropriate BMI cut-points for Asians, Singapore, 2002

\section{Acknowledgement}

We are grateful to all the subjects who participated in the CRISIS study. Nestle Foundation, Lausanne, Switzerland and the International Atomic Energy Agency, Vienna, Austria provided financial support. We would like to thank social workers, Mr. TM Deokar, Mr. AJ Bhalerao, Mr VA Solat and Mr. AB Gaikwad for their hard work. Mr. CV Joglekar helped in data management and Mrs. PC Yajnik provided administrative supervision. 


\section{References}

1. Ramaiya KL, Kodalia VR, Alberti KG. Epidemiology Of Diabetes In Asians of Indian subcontinent. Diabetes Metab Rev 1990; 6(3): 125-146.

2. Gupta R, Gupta VP. Meta-analysis of coronary heart disease prevalence in India. Indian Heart J. 1996; 48(3): 241-245.

3. Ramachandran A, Snehalatha C, Kapur A, Vijay V, Mohan V, Das AK, Rao PY, Yajnik CS, Prasanna Kumar KN, Nair JD; Diabetes Epidemiology Study Group in India (DESI). High prevalence of diabetes and impaired glucose tolerance in India: National Urban Diabetes Survey. Diabetologia 2001; 44(9): 1094-1101.

4. Deurenberg-Yap M, Schmidt G, van Staveren WA, Hautvast JG, Deurenberg P. Body fat measurement among Singaporean Chinese, Malays and Indians: a comparative study using a four-compartment model and different two-compartment models. Br. J Nutr. 2002; 85(4): 491-498.

5. Chowdhury B, Lantz H, Sjostrom L. Computed tomography-determined body composition in relation to cardiovascular risk factors in Indian and matched Swedish males. Metabolism 1996; 44: 634-644.

6. Banerji MA, Faridi N, Chaikn RL, Lebovitz HE. Body composition, visceral fat, leptin, and insulin resistance in Asian Indian men. J. Clin. Endocrinol Metab 1999; 84: 137144.

7. Chandalia M, Abate N, Garg A. Relationship between generalized and upper body obesity to insulin resistance in Asian Indian men. J Clin Endocrinol Metab 1999; 84(7): 2329-2335.

8. Yajnik CS, Fall CHD, Coyaji KJ, Hirve SS, Rao S, Barker DJP, Joglekar C, Kellingray S. Neonatal anthropometry: The thin-fat Indian baby, The Pune Maternal Nutrition Study. International Journal of Obesity 2003; 26:173-180.

9. Prentice AM. The Doubly Labelled Water method for measuring energy expenditure: Technical recommendation for use in humans. A A consensus report by the IDECG Working group, Vienna, 1990\}. Section 3.5.1.ii: 27.

10. Borgonha S, Pitracchi C, Ferro Luzzi A, Shetty PS, Kurpad AV. Prediction of total body water in Indian men from anthropometry and bioelectrical impedance using deuterium dilution as reference. Annals of Human Biology 1997; 24 (4): 355-361.

11. Coward A. Calculation of pool sizes and flux rates. In Prentice AM ed. The Doubly labelled water method for measuring energy expenditure; Technical recommendations for use in humans. A consensus report by the IDGCG Working Group. Vienna 1990. Sec 4.3.2:59 \& Appendix 2.

12. Wang Z, Deurengerg P, Heymsfield DB. Cellular-level body composition model. A new approach to studying fat-free mass hydration. Ann N Y Acad Sci. 2000; 904: 306311.

13. Durnin JVGA, Womersley J. Body fat assessed from total body density and its estimation from skinfold thickness: measurement on 481 men and women aged from 16 to 72 years. Br J Nutr 1974; 32: 77-97.

14. Siri WE. Body composition from fluid spaces and density: analysis of methods. In techniques for measuring body composition, Edited by Brozek $\mathrm{J}$ and Henschel $\mathrm{A}$ (Washington, DC: National Academy of Sciences NRC) 1961; 223-244.

15. National Institutes Of Health, Bioelectrical impedance analysis in body composition measurement, Technology Assessment Conference Statement, December 12-14, 1994. US Department of health and human service.

16. Bland JM And Altman DG: Statistical methods for assessing agreement between two methods of clinical measurement, Lancet 1986; I: 307-310. 
17. Kurpad AV, Borgonha S, Shetty PS, Ferro-Luzzi A. Body composition of chronically energy deficient human males by a 3 compartment model. Indian J Med Res. 1999; 109: 56-66.

18. WHO. Obesity: preventing and managing the global epidemic. Report on a WHO Expert Consultation on Obesity, Geneva, 3-5 June, 1997. WHO/NUT/NCD/98.1. Technical Report Series Number 894. Geneva: World Health Organization, 2000.

19. WHO expert consultation. Appropriate body-mass index for Asian populations and its implications for policy and intervention strategies. The Lancet 2004; 363: 157-163.

20. Deurenberg-Yap M, Schmidt G, van Staveren WA, Hautvast JG, Deurenberg P. Body fat measurement among Singaporean Chinese, Malays and Indians: a comparative study using a four-compartment model and different two-compartment models. Br. J Nutr. 2002; 85(4): 491-498.

21. Wang J, Thornton JC, Russell M, Burastero S, Heymsfield S, Pierson RN Jr. Asians have lower body mass index (BMI) but higher percent fat than do whites: comparison of anthropometric measurements. Am J Clin Nutr 1994; 60(1): 23-28. 
Table 1. Anthropometric characteristics of the subjects studied in the comparative study and the parent group

\begin{tabular}{|c|c|c|}
\hline & Study group $(\mathrm{n}=141)$ & Parent group $(\mathrm{n}=447)$ \\
\hline Age $(\mathrm{y})$ & $39.3(6.2)$ & $38.9(6.0)$ \\
\hline Height $(\mathrm{cm})$ & $165.5(6.1)$ & $164.9(6.4)$ \\
\hline Weight $(\mathrm{kg})$ & $60.0(10.7)$ & $60.1(11.9)$ \\
\hline BMI $\left(\mathrm{kg} / \mathrm{m}^{2}\right)$ & $21.9(3.7)$ & $22.6(3.9)$ \\
\hline
\end{tabular}

Values are Mean (SD) 
Table -2: Body composition parameters in the study group $(n=141)$ In a table like this, it would be worth including additional data (eg ranges, $10^{\text {th }} / 25^{\text {th }} / 75^{\text {th }} / 90^{\text {th }}$ centile)

\begin{tabular}{|l|l|}
\hline Parameter & Mean (SD) \\
\hline TBW by Anthropometry $(\mathrm{Kg})$ & $33.4(4.3)$ \\
\hline TBW by BIA $(\mathrm{Kg})$ & $31.8(3.8)$ \\
\hline TBW by $\mathrm{D}_{2} \mathrm{O}(\mathrm{Kg})$ & $32.7(4.3)$ \\
\hline Body fat by Anthropometry $(\mathrm{kg})$ & $14.3(5.9)^{*}$ \\
\hline Body fat by BIA $(\mathrm{kg})$ & $16.5(8.1)^{*}$ \\
\hline Body fat by $\mathrm{D}_{2} \mathrm{O}(\mathrm{kg})$ & $15.3(6.4)$ \\
\hline Body fat by Anthropometry $(\%)$ & $23.0(6.2)^{*}$ \\
\hline Body fat by $\mathrm{BIA}(\%)$ & $26.0(9.3)^{*}$ \\
\hline Body fat by $\mathrm{D}_{2} \mathrm{O}(\%)$ & $24.6(7.0)$ \\
\hline
\end{tabular}

\begin{tabular}{|l|}
\hline Formatted: Superscript \\
\hline Formatted: Superscript \\
\hline Formatted: Superscript \\
\hline Formatted: Superscript \\
\hline
\end{tabular}

* Significantly different from $\mathrm{D}_{2} \mathrm{O}, \mathrm{p}<0.001$. 
Figure1a. Bland and Altman Plot: Comparison of fat mass between criterion method and anthropometry.

I think you should take the opportunity of showing ALL the comparisons AND correlations AND Bland-Altman plots for all methods against criterion method, and correlations of all 3 against BMI.This is a very visual set of data, so oit needs lots of figures.

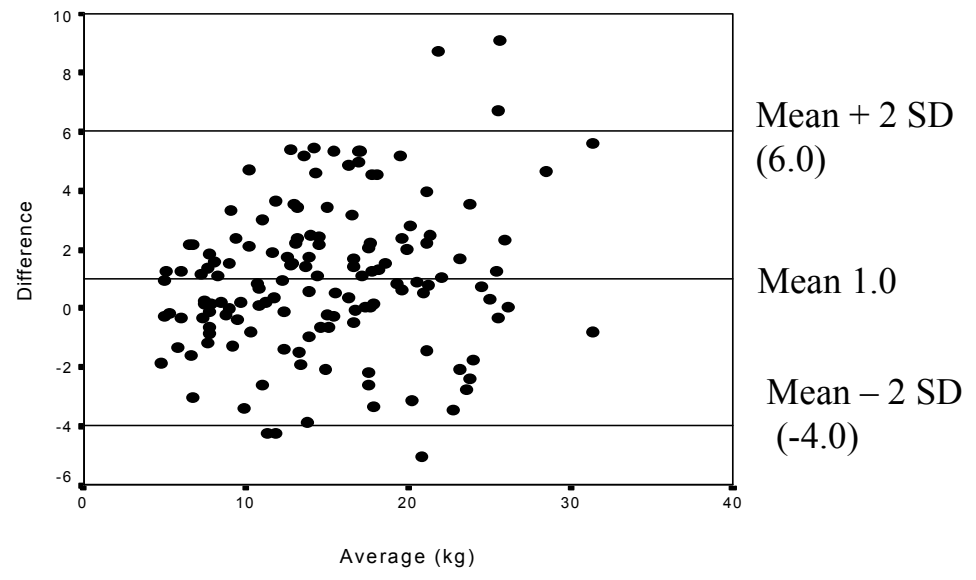


Figure - 1b. Bland and Altman Plot: Comparison of fat mass between criterion method and BIA.

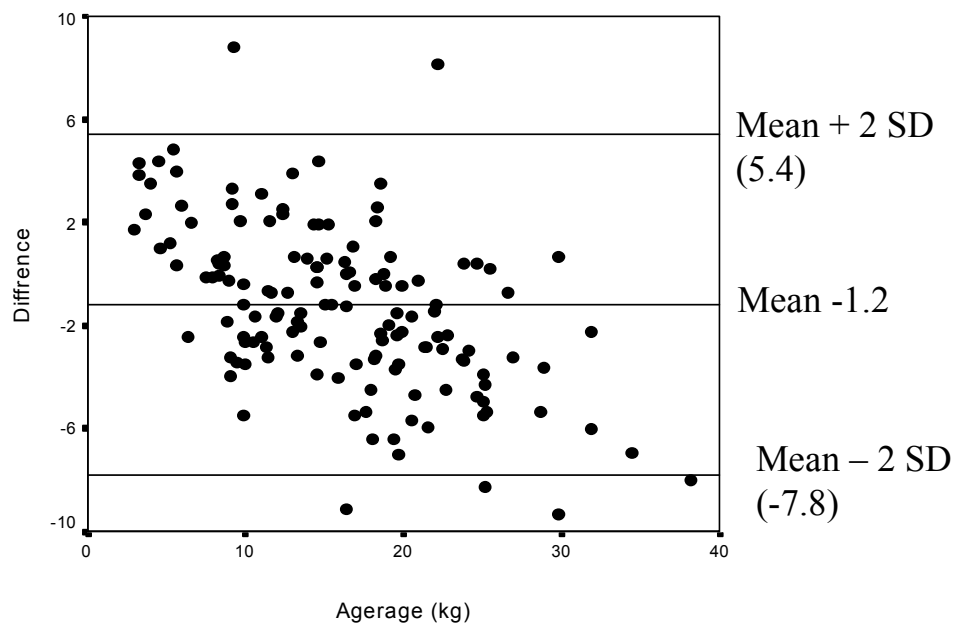


Figure-2 Shows scatter diagram of body fat $\%$ by $\mathrm{D}_{2} \mathrm{O}$ vs BMI with no difference line

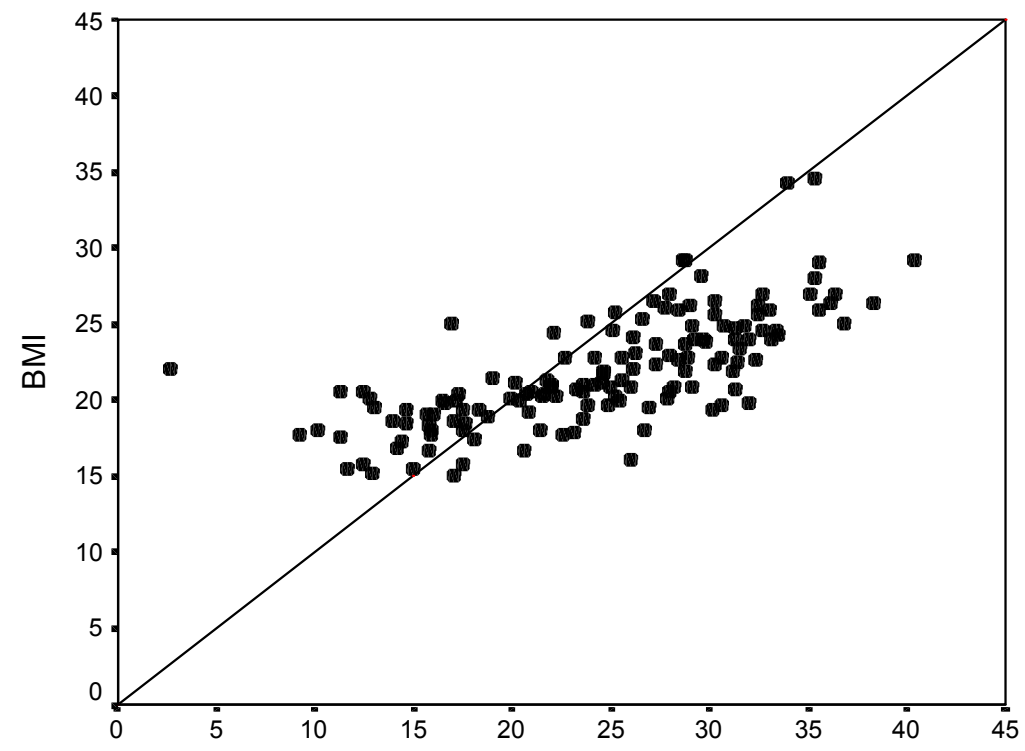

Fat $\%$ by D2O 